\title{
JULIO LLAMAZARES O LA HISTORIA QUE SE BORRÓ \\ JULIO LLAMAZARES OR THE HISTORY THAT WAS DELETED
}

KONSTANTINOS PALEOLOGOS ${ }^{1}$

Universidad Aristóteles de Grecia

\section{Resumen}

Julio Llamazares «habló» en su obra del ocaso de toda una civilización, la de los pueblos montañosos del norte de España que se vieron abandonados por sus pobladores a causa de la emigración masiva de los años ' 50 y ' 60 , y nos enseñó que la Literatura puede ser, más que la Historia, la única manera posible de dar voz a seres que son los últimos de su estirpe.

Palabras clave: Julio Llamazares, memoria colectiva, recreación literaria

\begin{abstract}
Julio Llamazares, in his work, "speaks" of the sunset of a whole civilization, that of the mountain villages of northern Spain which were abandoned by their inhabitants because of the mass immigration in the 1950s and 1960s, and showed us that Literature can be, even more than History, the only possible way to give voice to people who are the last of their generation.
\end{abstract}

Key words: Julio Llamazares, collective memory, literary recreation

Yo soy escritor, cuento historias para pensar y hacer sentir, no escribo para reivindicar nada. Julio Llamazares ${ }^{2}$

Si el tiempo se pudiera fragmentar, nuestra historia empezaría en la década de los '50 cuando, fundamentalmente por motivos económicos, se inician los desplazamientos masivos de la población española rural hacia los diversos núcleos industrializados del país y el gran éxodo hacia el extranjero (principalmente Alemania, Francia y Suiza). Según datos publicados por Martínez Ruiz, Maqueda \& de Diego (1999: 211), entre 1951 y 1970 Andalucía pierde alrededor de 1.400 .000 habitantes, las dos Castillas en torno a unos 800.000 habitantes cada una y, por último, Extremadura y Galicia unos 500.000 habitantes cada una. Estos "huidos de la pobreza" vienen a establecerse principalmente en Madrid y Cataluña (casi 1.000.000 de individuos se

\footnotetext{
${ }^{1}$ Universidad Aristóteles de Grecia. Correo-e: kkpp@hol.gr. Recibido: 23-06-2017. Aceptado: 13-11-2017.

${ }^{2}$ En Ortiz (2015).
} 
instalan en cada una de ellas), en el País Vasco y la Comunidad Valenciana (unos 500.000 en cada una de ellas), al mismo tiempo que entre 200.000 y 250.000 personas anuales, por término medio, emigran a países extranjeros (sin contar con casi 1.000.000 de emigrantes temporales).

Como apunta Justicia Segovia (1987:31) “a partir de 1950, y con mayor intensidad desde 1960, la sociedad española reinicia su fase de transición definitiva de una sociedad preindustrial, de base rural, a otra industrial, de base urbana". En la década de los '60 empiezan a notarse los síntomas de este cambio radical en la estructura del país; son los años del "bienestar subversivo" basado, sobre todo, en el desarrollo de la industria y el flujo de inversiones extranjeras. La nueva clase media española que se está creando en aquella época, sostiene Rodríguez Zúñiga (1985: 106), se compone de "grupos sociales que aspiran al tipo de vida europeo, que comienzan a viajar al extranjero, que toman contacto con la vida europea mediante la afluencia de turistas que determinadas zonas empiezan a recibir". Esta circunstancia unida al crecimiento de la demanda educativa, la conversión de las Universidades en lugares en los que se intenta practicar libertad y creatividad, la secularización de la sociedad española y la progresiva incoherencia que se va notando entre el aparato político-institucional del franquismo y la nueva sociedad hizo que España se convirtiera paulatinamente "en un país laico, con una ética civil centrada en el respeto de los derechos de la persona y una mayor tolerancia en el ámbito de las relaciones sexuales", (García de Cortázar \& González Vesga,1994: 621).

El desarrollo de los años '50 y'60, también conocido como "milagro español”, no obstante, generó problemas sociales extremadamente agudos: “Galicia, las dos Castillas, Andalucía, Extremadura, Aragón y Canarias siguieron estando subdesarrolladas, y su situación se agravó con el éxodo rural a consecuencia de la mecanización de la agricultura", (Pérez, 2006: 657). Este éxodo masivo provocó el abandono o el deterioro de centenares de pueblos, circunstancia esta que cambia para siempre el perfil de España y crea "desequilibrios regionales, abandono de la agricultura, emigración a Europa de casi dos millones de españoles, urbanización improvisada y desordenada, sistema fiscal regresivo", (Fusi,1996: 41). Como apunta el historiador francés Pierre Vilar (1990: 165),

durante quince años (1940-1955), el expolio de las clases trabajadoras se hizo sin contrapartida, de donde surge una acumulación masiva de capital que los bancos invierten. El despegue económico revelará entonces las disparidades sectoriales. En el campo, el minifundio sigue siendo miserable; el latifundio paga mejores jornales a su mano de obra, pero la mantiene proletarizada entre el éxodo y el paro.

El régimen se veía cada vez más impotente a la hora de asumir los cambios y hacer frente a las preocupaciones de los ciudadanos ${ }^{3}$ y la situación se agravó a causa de la recesión de los años '70 debido, en parte, a la denominada "crisis del petróleo",

\footnotetext{
${ }^{3}$ Como señala Torres del Moral, «la legislación de desarrollo de la Ley Orgánica del Estado de 1967 puso de manifiesto la inutilidad del esfuerzo de los sectores aperturistas del régimen franquista. Una dictadura con ciertos tintes feudales como aquella no podía intentar edificar las bases de una moderna sociedad de consumo sin agrietarse», (1988: 2).
} 
acaecida a finales de 1973. A mediados de los '70, pues, España, "había dejado de ser, desde hacía quizás más de una generación, el país eminentemente agrícola que había alimentado el caciquismo y el clericalismo de finales de siglo, y que había definido, en fin, el secular atraso español", (Subirats,1995: 11); pero aun así, el panorama poco antes de la muerte del caudillo es desolador:

en un clima de final de reinado, las huelgas se convierten en moneda corriente, alimentadas por una inflación que llega al $20 \%$ y un paro que ya afecta al $5 \%$ de la población activa. La crisis interrumpe la emigración y reduce las remesas. El turismo preocupa; incluso se aprecia una disminución de la inversión extranjera. Mientras la factura energética va aumentando, la balanza de pagos se derrumba y la peseta se debilita, (Témime, Broder \& Chastagnaret,1982: 363).

La muerte de Franco, en 1975, desencadenó, como era de esperar, una serie de transformaciones en todos los aspectos de la vida política, social y económica de España; así, a finales de la década de los '70, principios de los '80, se respiraba en el país una imperiosa necesidad de borrar el pasado, de que todo fuera nuevo: nuevo régimen, nueva constitución, nuevas costumbres... Efectivamente, España en aquella época, era un país que había ahuyentado los fantasmas del pasado y empezaba a encontrar su sitio en Europa. Pero al mismo tiempo, como es natural, todo ese cambio afectó profundamente a la sociedad española. Según Francisco Rico (1991),

la ideología empezó a ser sustituida como marihuana del pueblo no sólo por el deporte, los viajes y la buena mesa, sino además por las exposiciones, los bellos libros, la ópera, los conciertos. [...] Por el atractivo escaparate, en suma, de una oferta cultural tan variopinta. [...] Los ciudadanos se concentraban con creciente exclusivismo en los intereses particulares, en el ocio, en la vida privada.

Como es natural, la literatura no se quedó ajena a esa avalancha de cambios. A principios de la década de los '80, comienza a hablarse de la existencia de una promoción de jóvenes narradores: la "Nueva narrativa española de los '80". En sus orígenes estrictos esta etiqueta agrupó a un puñado de escritores y escritoras jóvenes (o menos jóvenes) que habían logrado despertar la atención tanto de los editores como de los medios de comunicación - algo similar, pero sin el mismo éxito comercial, ocurría al mismo tiempo en el campo de la poesía con los llamados postnovísimos (Blanca Andreu, Luis García Montero, Rosa María Pereda, etc.). Intentar confeccionar una lista exhaustiva de los supuestos miembros de aquella promoción es empresa harto complicada; con más frecuencia se mencionaban los nombres de Jesús Ferrero, Ignacio Martínez de Pisón, Julio Llamazares, Alejandro Gándara, Almudena Grandes, Rosa Montero, Cristina Fernández Cubas, Antonio Muñoz Molina, Javier Marías; sin embargo, hay bastantes más escritores que se citaban con menor asiduidad, como son los casos de Luis Landero, Mercedes Abad, Pedro Molina Temboury y de bastantes más.

Con respecto al momento en el que dichos autores irrumpen en el mercado, se barajan varias fechas, aunque bien es verdad que la mayoría de los estudiosos en la materia consideran que fue Bélver Yin de Jesús Ferrero, editada en 1981, la primera novela publicada de dicha promoción: “Creo no exagerar si sitúo a Jesús Ferrero como 
signo de este nuevo fenómeno. En 1981 la aparición de su primera novela, Bélver Yin, convocó un revuelo de público y crítica", (Bértolo, 1989: 51).

Entre los miembros de este grupo, que se tildaron, injustamente en muchos de los casos, de cultivadores de una narrativa light que se evadía de la realidad circundante y que, por lo tanto, apostaba por el olvido, es decir, una narrativa escrita precisamente para captar el interés de unos ciudadanos que preferían pasar de página y dejarse atrás el largo invierno del franquismo, se incluía un poeta/narrador ("nacido en un lugar que está bajo el agua", como él mismo ha declarado en numerosas entrevistas) que desde La lentitud de los bueyes (su primer poemario, editado en 1979) hasta Distintas formas de mirar el agua (su novela más reciente, publicada en 2015), pasando por hitos de la narrativa española de los '80 como La lluvia amarilla, apostó por la recuperación de la memoria colectiva de las gentes de los pueblos montañosos del norte de España que se vieron obligadas, como hemos visto al inicio de este ensayo, a abandonar sus hogares por razones de sustento o por motivos más prosaicos pero igual de crueles, como puede ser la construcción de una presa en la España franquista de mediados del siglo pasado.

Julio Llamazares, este es el escritor del que estamos hablando, nació en 1955 en Vegamián, un pueblo ganadero de la provincia de León donde su padre trabajaba de maestro. Su familia, dos años después, al igual que el resto de los habitantes del pueblo, se vio obligada a mudarse a causa de la inminente construcción de un pantano, el del Porma, hoy, oficialmente, Embalse Juan Benet, en la zona (Vegamián, desde 1968, descansa sumergido en las aguas de dicho embalse). La familia, se trasladó, en 1957, a Olleros de Sabero, un pueblo minero de León, que por aquella época empezaba su despegue económico coincidiendo con el auge de las minas de carbón. Precisamente Olleros fue el escenario de la tercera novela de Llamazares, Escenas de cine mudo, editada en 1994.

Llamazares, vivió en Olleros hasta 1967, año en el que, a los 12 años, se fue a seguir sus estudios a Madrid, a un colegio de Franciscanos Capuchinos. Esta etapa dura cuatro años y, en 1971, a los 16 años, se instala en León para estudiar el curso anterior al ingreso a la Universidad. Al final, accede a la carrera de Derecho, y cursa los primeros años en León y, luego, los dos últimos, en Oviedo y Gijón donde pasó tres años de su vida.

A mediados de la década de los '70 inició su colaboración con la Radio Popular de León. En aquel ámbito surgió, en 1975, el grupo literario «Barro» (Mercedes Castro, Manuel Arias, José Carlón, Miguel Escanciano y otros) que en 1976 edita Barro. Poesía, un volumen en el cual se incluyen poemas de Llamazares. En ese mismo año, 1976, Llamazares obtuvo, también, el premio Nacional de Poesía Universitaria. Del grupo "Barro", de algunos de sus componentes al menos, surgieron al año siguiente los Cuadernos Leoneses de Poesía (Llamazares, Carlón, Escanciano y otros) que según Víctor García de la Concha (1986: 30), y a pesar de la corta vida de la revista (siete números publicados entre noviembre-diciembre de 1977 y septiembre-octubre de 1979), "sirvieron de palestra a las voces más auténticas de la joven poesía leonesa". Fruto 
de aquella época, primavera de 1978, es su primer libro de poesía, La lentitud de los bueyes, que obtuvo el premio “Antonio González de Lama” de 1978 y que fue editado al año siguiente, 1979. A finales de 1978, vuelve a instalarse en León y a colaborar con periódicos locales. En enero de 1981 se instala definitivamente en Madrid.

En la capital, empezó a colaborar con varios periódicos y revistas (Diario 16, El Urogallo y otros) y termina su libro El entierro de Genarín, un evangelio negro sobre la procesión que se celebra en León cada Jueves Santo, en memoria de un esperpéntico personaje local. Al año siguiente, aparece su segundo libro de poesía titulado Memoria de la nieve, galardonado con el premio “Jorge Guillén” de 1982. Por aquella época solicita y obtiene la Ayuda a la Creación Literaria que concedía el Ministerio de Cultura a jóvenes escritores. Producto de aquella ayuda económica, (y de su inspiración, claro), fue su primera novela, Luna de lobos, que la terminó en 1984. Mientras tanto, seguía cosechando premios; el premio "Numancia" de periodismo de 1983 y el premio "Ícaro" de literatura del mismo año.

En 1983, empieza su andadura como guionista cinematográfico. Eso ocurrió cuando el director José María Martín Sarmiento le pidió (como a otros cuatro escritores leoneses) un relato para su película El Filandón (filme que se estrenó en 1984 y en el cual Llamazares hace, también, su aparición como actor). Llamazares aportó un guión, titulado, al igual que el poema en el que se inspiró, "Retrato de bañista"4. A finales de 1984, colaboró en el programa “Tiempos Modernos" de la segunda cadena de TVE, un programa de contenido cultural dirigido por Miguel Rubio.

En marzo de 1985, Seix Barral edita Luna de lobos. En el otoño de 1986, empieza su colaboración con el diario El País por mediación del por aquel entonces director de la editorial Alfaguara, Juan Cruz. En 1985, y en colaboración con el director Julio Sánchez Valdés, escribe un guión cinematográfico basado en Luna de lobos. La película, bajo el mismo título, se estrena en 1987. Su segunda novela, La lluvia amarilla, aparece en 1988 y dos años más tarde sale El río del olvido, un libro basado en las notas de un viaje que el escritor había realizado por los pueblos de la comarca leonesa del río Curueño en 1981. En octubre de 1991, se edita En Babia, un libro que reúne los principales reportajes y artículos de opinión y de viajes de Llamazares que habían aparecido previamente en El País, El Urogallo y otros medios. En 1994, ve la luz Escenas de cine mudo su tercera novela y el mismo año escribe, junto con el director Felipe Vega, el guión de la película El techo del mundo cuyo estreno se produjo a finales de 1995.

Hemos llegado, pues, a 1995, año en el que Llamazares publica tres libros. El primero, salió en marzo y se trata del ya mencionado Retrato del bañista, el poema-guión que el escritor leonés había escrito para la película El Filandón de Martín Sarmiento. El segundo se presentó en mayo, bajo el título Nadie escucha, y es la segunda entrega de artículos periodísticos del autor; por último, a finales de octubre, llegó a las librerías

\footnotetext{
${ }^{4}$ Fragmentos de este poema, fruto de una visita del autor a las ruinas de su pueblo que habían emergido gracias a un momentáneo vaciado del pantano y que terminó convertido en guión cinematográfico, aparecieron en la revista albaceteña Barcarola, y más concretamente en los números 15 (marzo de 1984) y 19 (diciembre de 1985).
} 
En mitad de ninguna parte, un libro recopilatorio de los cuentos del escritor leonés que como él mismo confiesa en el prólogo del libro, casi todos habían sido escritos por encargo, (pág. 13).

En 1998, Llamazares publica dos libros, la colección de relatos Tres historias verdaderas y Trás-os-montes, el relato de un viaje por la homónima región montañesa de Portugal. Al año siguiente, 1999, el escritor leonés colabora como guionista con la directora Iciar Bollain en la realización de la película Flores de otro mundo (el guión se edita por la editorial madrileña Páginas de Espuma en 2000). De 1999 es también otro relato de viaje del autor, titulado Cuaderno del Duero.

Tras un prolongado «silencio» de casi seis años, Llamazares se estrena en el siglo XXI con su novela El cielo de Madrid (la primera suya que no está ambientada en un paisaje rural). La siguen dos recopilaciones de artículos de prensa, esto es, Modernos y elegantes, en 2006, y Entre perro y lobo, en 2008. Ese mismo año, ve la luz el primer tomo de su proyecto más ambicioso: Las rosas de piedra, un viaje en el tiempo y en la geografía por todas las catedrales de España ${ }^{5}$.

En 2009, veintisiete años más tarde de la aparición de su anterior poemario, Llamazares edita un libro de poesía, es decir, Versos y ortigas. En él, se reúnen sus tres títulos fundamentales, La lentitud de los bueyes, Memoria de la nieve y Retrato de bañista, y se añaden dos nuevos grupos de poemas: uno anterior, "Los inicios", que recoge los escritos entre 1973 y 1978, y otro posterior, “Las ortigas” (1984-2008).

Ya en la presente década, Llamazares ha publicado cinco libros más: una recopilación de relatos, Tanta pasión para nada (2011); dos relatos de viajes, Atlas de la España imaginaria (2015), un atlas nada imaginario en el que se siguen las huellas de la toponimia de algunos de los refranes más famosos de la lengua española, y El viaje de Don Quijote (2016), una serie de artículos que el autor publicó en El País y en los que se reproduce la ruta del famoso hidalgo por la Mancha que realizó Azorín en 1905; y dos novelas, Las lágrimas de San Lorenzo, en 2013, y Distintas formas de mirar el agua (su "reencuentro" con las montañas leonesas) en 2015, finalistas ambas del Premio de la Crítica de Castilla y León.

En su dilatada carrera como escritor, no en vano están a punto de cumplirse 40 años desde la publicación de su primer libro, Llamazares, un autor de ritmo pausado en la edición de sus libros, "habló" en muchas ocasiones del ocaso de toda una civilización, la de los pueblos montañosos del norte de España que se vieron abandonados por sus pobladores, pese al arraigo vital de estos últimos con su paisaje, a causa de la forzada emigración masiva hacia las grandes ciudades y las zonas industriales en la España de los años ' 50 y '60, y nos enseñó, o por lo menos esta es la lectura que queremos hacer de ella en la presente ocasión, que la Literatura puede ser, más que la Historia, la única manera posible de dar voz a seres sacrificados en el nombre del progreso. Para verificar esta tesis, recurriremos a las reseñas de los críticos literarios y lo dicho por el propio autor acerca de cuatro libros suyos (que, nos atreveríamos a sostener, constituyen una

\footnotetext{
${ }^{5}$ Actualmente el autor está ultimando la edición del segundo, y último, tomo.
} 
atípica trilogía, puesto que los dos primeros, desde muy pronto, empezaron a circular en el mercado en edición conjunta), esto es, sus poemarios La lentitud de los bueyes y Memoria de la nieve, La lluvia amarilla, su novela emblemática de los años '80, y su última, hasta la fecha, novela, Distintas formas de mirar el agua.

Pero antes, un brevísimo inciso para matizar la relación de Julio Llamazares con el marbete de la "Nueva narrativa española de los ' 80 ", al que nos hemos referido hace algunos párrafos y en cuya nómina había sido incluido el autor en aquel período: es curioso, pero los mismos críticos que lo insertaban en dicho grupo no dudaban, al mismo tiempo, en señalar que en su obra en general, y particularmente en sus novelas, Llamazares no cumplía con bastantes de los tópicos que solían acompañar la joven novelística española de la época, y principalmente con la tendencia a la evasión de la realidad circundante, la ambientación urbana y la temática light ${ }^{6}$. Por su parte, el escritor leonés bastante pronto, esto es, desde finales de los '80, empezó, él también, a tomar distancias de aquel supuesto grupo: "Ya sabemos que la prensa tiende a etiquetar, lo cual favorece su trabajo", señalaba en una entrevista concedida a Carlos Iriart en 1988.

\section{Poemarios}

Por el paisaje gris de mi memoria, cruzan arrieros sin retorno, pastores y alfareros olvidados, bardos ahogados en el miedo lacustre de sus propias leyendas.

Memoria de la nieve

Según la inmensa mayoría de los críticos literarios que se han ocupado de su obra, Julio Llamazares es un poeta que dejó relativamente pronto de escribir poesía en verso para pasar, a partir de 1985, con Luna de lobos, a la poesía en prosa. Antes de este momento, Llamazares había publicado, como ya hemos señalado, dos poemarios que habían causado sensación: La lentitud de los bueyes en 1979 y, tres años más tarde, Memoria de la nieve (las dos obras, en 1985, se editaron conjuntamente en Hiperión). En ellos hablaba de la desaparición de la cultura rural de su tierra. García Martín, (1992: 115) detectaba en ambos poemarios el carácter épico de la poesía llamazariana y señalaba que este radica "en el intento de rescate de una memoria colectiva, de una ancestral sabiduría; en sus versos encontramos la brumosa evocación de una edad de oro situada, al margen de la historia, en sus natales montañas leonesas"; Luis Antonio de Villena, a su vez, en Postnovísimos, (1986: 26), comentaba que "no otra es la tradición que ha sabido usar, personal y atinadamente (sobre todo en su segundo libro, Memoria de la nieve), Julio Llamazares, creando la imaginería de una personal vivencia unida al norte, [...] que la tradición del versículo. Una lírica con atisbos de épica". Parreño (1984: 6), coincidiendo con de Villena, subraya que la poesía de Llamazares “se

${ }^{6}$ «Llamazares [...] quizá por su procedencia de una de las zonas más deprimidas y olvidadas de España (la comarca montañesa de León) ha desarrollado una obra narrativa poco comparable, hasta ahora, a la de sus compañeros de generación», (Izquierdo, 1995: 56). 
construye con recuerdos, sueños y naturaleza. Creo que la naturaleza en su obra cobra una dimensión extrañamente mítica, una personalidad. Con sobriedad, en versículos, con un vocabulario selecto de voces campesinas, arma un escenario por el que cruzan en soledad vivos y muertos".

Otro autor, Izquierdo, (1995: 57), no duda en afirmar que en el primer poemario del escritor, "se pueden rastrear los discursos existencialistas y neorrománticos que recorrerán toda su obra. [...] Para el Llamazares de La lentitud de los bueyes el tiempo quedará definido como lo auténtico frente a la inautenticidad que supone el comportamiento del ser que olvida, que se despreocupa".

Cabo Aseguinolaza \& Candelas Colodrón, (1986: 277), por su parte, y en una reseña sobre el segundo poemario de Llamazares, subrayaban que "como tema de Memoria de la nieve se perfila con definición la memoria. Se trata del intento, doloroso a veces, de recuperar un mundo que aparece inalcanzable»; Santos Ayuso, (1983), abundaba en lo mismo al señalar que

Julio Llamazares es un poeta de los paisajes fríos, legendarios, míticos, que hace suyo el tiempo y la historia, el recuerdo y la memoria de un pasado y un lenguaje, pero al mismo tiempo de interiores cálidos y consonantes con la tierra y escenario de sus vivencias. [...] Memoria de la nieve, de Julio Llamazares, es un canto épico a la tierra a través del tiempo y la memoria.

García (1983: 92-93), por su parte, califica Memoria de la nieve de «un viaje hacia el origen», e Izquierdo de una lucha "contra la alienación del ser ante una realidad que ni comprende ni controla. Una realidad construida por el ser, pero que ha escapado por completo de su dominio", (1995: 61).

Concluiremos esta pequeña incursión por los comentarios de los críticos que subrayan la vertiente testimonial de la obra poética del autor leonés con un comentario significativo de Dionisio Cañas (1989: 53) acerca del compromiso político de dicha obra:

lo que importa hoy al poeta joven es fascinar. Por lo tanto, mezcla lo falso y lo verdadero, abusa del artificio, busca la sorpresa y huye del didactismo. Aunque hay algunos poetas, como Luis García Montero y Julio Llamazares, que buscan a través del compromiso, social el primero y ecologista el segundo, una manera de escapar del cinismo social y político de nuestra poesía última.

Llamazares intentando "justificar" su poética declaraba en una entrevista: «Uno escribe siempre de lo que no tiene y de lo que ha perdido. Si hoy la realidad española es urbana, su memoria, en cambio sigue siendo agraria, y yo quiero ser coherente con mi propia memoria», (en Demicheli, 1988); y algunos años más tarde: "para escribir me apoyo en una memoria que va desapareciendo porque, como si de un río se tratase, la arrastra el paso del tiempo. Y yo trato de fijarla al escribir. La literatura sería un intento de lucha contra el paso del tiempo. Lo poco que salvamos del tiempo y de la memoria es la literatura", (en Roglan, 1990).

\section{La lluvia amarilla}

En la calle, la niebla se agarraba a las paredes y la humedad helada de la escarcha hacía ya invisible cualquier rastro reciente de pisadas. Un inmenso 
silencio llenaba todo el pueblo, introducía su larga

lengua sucia hurgando en la penumbra de las casas

la herrumbre del olvido.

Si los dos poemarios son el intento personal del poeta de llevar a cabo "la recreación romántica de la historia [de sus antepasados]", (Ayuso, 1983: 91), La lluvia amarilla es una larga y desordenada analepsis de un antihéroe (de un personajenarrador que pertenece a la misma cultura milenaria que se evoca en los poemarios) que estando al borde de la nada y a caballo entre la realidad y la locura, reconstruye, a través de los recuerdos que pueblan su memoria, su pasado y, de paso, el pasado de todo un pueblo.

Andrés de Casa Sosas, el protagonista, es el representante de un modo de vida en vías de extinción, si no ya extinguido, y él es plenamente consciente de ello: "en realidad, y pese a mis esfuerzos por mantener vivas sus piedras, Ainielle está ya muerto desde hace mucho tiempo", (pág. 75). Y es, al mismo tiempo, el personaje que se identifica con su pueblo hasta tales extremos que su inminente defunción significará, sin duda, también la desaparición total e irreversible de este último: "pero, dentro de poco, yo ya no estaré vivo. Dentro de unos minutos, de unas horas quizá -antes de que amanezca, en cualquier caso-, yo estaré ya sentado con los muertos en torno de la lumbre y Ainielle habrá quedado totalmente vacío, totalmente indefenso, a merced de esos ojos que, ahora, le vigilan", (pág. 128).

Este proceso de aniquilamiento, personal y colectivo, narrado por una conciencia delirante que ni siquiera sabemos si, en el momento de la narracion, pertenece a un ser vivo o a un fantasma (a una sombra), estará reconstruido mediante la memoria, memoria que junto a la muerte constituyen el eje principal de la novela, alrededor del cual se hilvana todo el relato. Ponte Far (1988), subrayaba en su reseña que

la novela se articula en torno a una trama argumental muy sencilla pero engañosa [...] engañosa porque parece que vamos a encontrarnos con una novela que pondrá énfasis en el aspecto sentimental y bucólico de un hecho literariamente muy explotable, y nos sorprendemos viéndonos situados ante un discurso novelístico profundo y duro, que va mucho más allá de cantar las excelencias de una vida o la tragedia de la desaparición de un pueblo de los Pirineos.

Nicolás Miñambres, (1988: 20), busca las conexiones entre los dos poemarios del escritor leonés y la novela en cuestión: "la novela encarna, con una forma lírica sobrecogedora, todas las obsesiones rurales que el autor ha apuntado en sus libros de poesía pero lejos de caer en el provincianismo literario. [...] El dramatismo lírico y simbólico preside el tratamiento de los pueblos abandonados".

De la raíz poética de La lluvia amarilla nos habla también Alonso (1992: 26), señalando que no es solo una novela realista ya que

en última instancia sus cimientos realistas (la historia, la cronología, los personajes, el espacio) se han convertido en ruinas, que la memoria palpa con color y nostalgia. Porque La lluvia amarilla es una proustiana búsqueda del tiempo y del espacio perdidos. De unos tiempos y de unos espacios que trascienden el dato objetivo para formar parte de un continuum de materia poética. 
Tras el éxito, de ventas y críticas, que cosechó La lluvia amarilla vino, como suele ocurrir en estos casos, un alud de entrevistas. Y en ellas, entre otras cosas, Llamazares dejó bien claro el tema de su novela: "La lluvia amarilla es una reflexión sobre la soledad y la memoria", (en Sanz, 1988).

Con respecto al empleo del monólogo, Llamazares, (en Lussón, 1988), lo justifica en los siguientes términos:

yo considero que cada tema novelesco determina un lenguaje y un punto de vista, o como dicen los escultores, que la obra está ya dentro del árbol y hay que desbrozar lo que sobra. El monólogo surge porque la sensación que me interesa transmitir sólo podía referirla a través de un sólo personaje. Lo que he hecho ha sido manipular ese monólogo con un personaje que está a caballo entre la realidad y la locura, que no sabe si está vivo o muerto, y que duda de su propia memoria, porque ya ha perdido la noción del paso del tiempo. Más que un monólogo se trataría de una transcripción de su memoria final.

A continuación, nos ocuparemos de una cuestión crucial, que ha marcado en general la trayectoria literaria de Llamazares, esto es, el empleo por parte de los críticos del calificativo "literatura rural" a la hora de referirse a su obra, a causa de la presencia, tan poderosa y tan bien descrita, de la naturaleza en ella. Veamos lo que opina al respecto Izquierdo: “en La lluvia amarilla, novela en forma de monólogo interior, se describe la naturaleza reflejando esta el estado de ánimo del protagonista. [...] La naturaleza conlleva el caos que terminará dominando la situación y que supondrá la recuperación de todo aquello que le pertenecía", (1995: 65).

Llamazares, por su parte, en una entrevista concedida al escritor Benjamín Prado (1988), explica de la siguiente manera su predilección por los paisajes montañosos y el protagonismo que ellos cobran en toda su obra:

he oído decir a Rafael Alberti que no es que sintiese nostalgia del mar, sino que escribía constantemente de él porque formaba parte de su personalidad. A mí me ocurre lo mismo con ese ámbito montañoso, nevado, que protagoniza mis novelas y está al servicio de mis diferentes estados de ánimo, dejándose interpretar de una manera subjetiva, convirtiéndose en una pasión, o lo que es igual, en una efermedad del corazón y del espíritu.

Con respecto a su intención, Llamazares aclara, (en Puente, 1988):

Soy un escritor representativo español, porque la sociedad española es una sociedad urbana con una memoria rural. [...] Lo que me interesa es hacer consciente la escisión entre el hombre y la naturaleza, que en este caso se trata, anecdóticamente, del último habitante de un pueblo abandonado, pero que si yo fuese neoyorkino, por ejemplo, a lo mejor una novela de parecida intencionalidad se refiriría a la soledad del inquilino del piso 202 de un rascacielos.

Más de un cuarto de siglo más tarde, y con La lluvia amarilla convertida ya en todo un clásico de la literatura española del siglo xx, Llamazares en una entrevista concedida a Rodríguez Marcos (2015), tras aclarar que su novela "no es la Biblia de la desaparición de un mundo", añade "La lluvia amarilla no es que fuera anacrónica, es que estaba fuera de lugar en la España oficial de entonces. Tú leías los periódicos y las novelas tenían que hablar de ciudades y detectives. Todos éramos muy modernos". 


\section{Distintas formas de mirar el agua}

Recuerdo las despedidas de los vecinos que aún resistían en Ferreras esperando a que el cierre de la presa los echara, algo que se anunciaba para muy pronto, y la partida desde la casa en aquel camión en el que íbamos toda la familia además de los animales y de nuestras pertenencias.

Si en La lluvia amarilla no hay otra voz que la de Andrés, el protagonista-narrador, en Distintas formas de mirar el agua, la sexta novela del autor, ocurre todo lo contrario: hablan todos los demás personajes, 17 en total, menos Domingo, el ya fallecido abueloprotagonista (representante él también, como el propio Andrés, de una civilización ya desaparecida), que han acudido a esparcir las cenizas del recién muerto patriarca de la familia por el pantano del Porma. Así describe dicha circunstancia Sanz (2015):

La lluvia amarilla, mítica novela de Llamazares, contaba la vida del último habitante de una aldea del Pirineo oscense y la contaba en primera persona, de tal manera que el lector iba conociendo la trama de una vida que estaba a punto de concluir. Pues bien, aquí, en Distintas formas de mirar el agua, lo que nos propone Llamazares son 16 miradas, comenzando por la de la mujer del protagonista, su viuda ya, y acabando por la de su hijo pequeño; entre medias, otros hijos, nueras, yernos, nietos, novios o novias de los nietos van sumando su voz, a veces desde la extrañeza, al ritual familiar de lanzar las cenizas del finado sobre la superficie del pantano que desalojó hace más de medio siglo a la familia de un valle leonés. De manera que esos monólogos se hacen en homenaje del hombre ya convertido en cenizas.

Llamazares, pues, con esta mirada caleidoscópica se reencontó con el éxito de crítica y de ventas, en 2015, con una novela coral de desarraigo que reúne todos los rasgos inconfundiblemente llamazarianos. Veamos dos comentarios al respecto; el primero de Ángel Basanta (2015):

Con esta novela Julio Llamazares (Vegamián, 1955) insiste en la veta que mejores frutos ha dado en su trayectoria narrativa, la que va de La lluvia amarilla (1988) a Las lágrimas de San Lorenzo (2013). Distintas formas de mirar el agua es otro admirable ejemplo de novela lírica por múltiples rasgos que van del perfecto endecasílabo destacado como título al abanico de subjetividades en su estrategia narrativa sustentada en 16 narradores complementarios, pasando por la tensión e intensidad emotiva y estilística, la eficacia de la elipsis y el predominio de formas externas breves tanto en la extensión de los capítulos como en la preferencia por frases cortas en párrafos nunca muy largos.

El segundo de Paz Olivares (2015):

de la muerte del paisaje y la memoria, nos habla Julio Llamazares en Distintas formas de mirar el agua. Lo viene haciendo desde sus primeros escritos. Desde el título de su primer poemario, La lentidud de los bueyes, de 1979, hasta esta última novela del 2015. Treinta y seis años escribiendo sobre el paso del Tiempo. Se ha enfrentado al tema desde todos los registros: libros de viaje, poemas, novelas, artículos periodísticos, crónicas, ensayos, guiones... todos escritos desde el dolor del regreso, desde el tono subjetivo y nostálgico del romántico.

Mainer, (2015), subraya el hecho de que

Llamazares no cuenta sus propios recuerdos, por supuesto, pero seguro que esta excelente novela coral ha sido de gestación lenta. Su acusado interés de siempre por la larga agonía de la vida rural española no busca un testimonio político, ni siquiera sociológico; de estos destinos 
de desarraigo le importa más la perduración de los lazos vitales y la fuerza de la resignación laboriosa;

por su parte Val (2015) hace hincapié en el valor testimonial de la novela cuando apunta que "Llamazares, una vez más, nos recuerda la importancia y la fuerza de lo primario, la solidez de los sentimientos desnudos, la altura que alcanza la literatura cuando habla de cosas que son verdad".

Apuntábamos al inicio de este ensayo que "la Literatura puede ser, más que la Historia, la única manera posible de dar voz a seres sacrificados en el nombre del progreso", Llamazares escribe justamente desde esta convicción (en Pintor7 , 2015: 45):

Julio Llamazares habla de la pérdida de la identidad en el ámbito rural pero, en general, en nuestra sociedad. [...] Llamazares se traslada al pasado y duda de la realidad en la que vivimos. El autor constata en su nuevo libro que la verdad no existe y le comenta al público que la memoria histórica de un país se encuentra en su literatura.

Julio Llamazares, en las entrevistas que concedió para la promoción de la novela, sostuvo que la novela en cuestión "desarrolla dos grandes temas: la relatividad de nuestra realidad y el desarraigo, ese destierro profundo y sin posibilidad de volver porque ya no existe el lugar", (en Plaza, 2015); para añadir en otra entrevista: "el personaje principal es un Ulises que no puede volver porque Ítaca ha dejado de existir, y solo regresa al pantano después de muerto y en forma de cenizas", (en Mendoza, 2015).

Efectivamente "Ítaca” ya no existe; el abandono del mundo rural español fue (y en bastantes casos sigue siendo) una "enfermedad crónica y degenerativa en muchas comarcas [españolas]", (Peñones Díaz, 2003), y significó el deterrioro o la pérdida de muchas culturas ancestrales en Castilla, Aragón, Extremadura y otras comunidades que estaban basadas en la economía agraria. Julio Llamazares, (en Castro, 1988), ha querido con y en su literatura dejar constancia de este cambio brutal que sacudió España a mediados del siglo xx y que él llegó a vivir:

yo tengo la idea de que todo lo que escribo parte de mi propia memoria y de la memoria colectiva a la que se entronca mi memoria, pero teniendo en cuenta que la memoria no es algo objetivo, no es algo real, sino que es algo que evoluciona, que se modifica y, en el fondo, es una gran mentira sobre la que asentamos nuestra personalidad. La memoria se inventa, se deforma, se recrea y en el proceso de reconstrucción de mi memoria -que eso y no otra cosa es la literaturaa la vez que me voy dando cuenta que mi memoria es la de una destrucción.

Para añadir algunas décadas más tarde (en Rodríguez Marcos, 2015):

La memoria histórica de un país es su literatura, y su arte. Se ha reducido a la Guerra Civil, pero memoria histórica también son los pantanos, la expulsión de los judios... Estar en contra de la memoria es como estar en contra de pensar o de soñar. Te pueden obligar a todo menos a no recordar, o a recordar. La vida se resume en una lucha entre memoria y olvido, y el trabajo de los escritores es recuperar todo lo que puedan del peso del olvido.

Julio Llamazares es el bardo, afortunadamente no ahogado, de un mundo pasado, marginal, destruido, borrado; sin embargo, lo importante en su obra, lo que la convierte en una obra universal e intemporal, es que en su literatura no hay ni un

${ }^{7}$ Pintor transcribe en estilo indirecto fragmentos de las charlas que mantuvo Llamazares con sus lectores en los actos de presentación de su novela en Galicia. 
atisbo de nostalgia, de deseo de recuperación de un mundo perdido; escribe, eso sí, con el firme deseo de perpetuar la memoria de una cultura (en una época en la que es más cómodo apostar por la desmemoria), de la cual se siente partícipe, sabiendo, no obstante, que el olvido es el único desenlace posible.

\section{BIBLIOGRAFÍA}

Andrés Alonso, R. M. (1992): “La lluvia amarilla”, en AA.VV. (1992) Julio Llamazares, memoria, poesía, símbolo, Zaragoza, IberCaja y Ministerio de Educación y Ciencia: 23-30.

Ayuso, S. (1983): “Poesía de la tierra y el tiempo. Julio Llamazares y José Carlón”, Cuadernos del Norte, 22, 90-91.

Basanta, Á. (2015): “Distintas formas de mirar el agua, Julio Llamazares", El Cultural, 27 de febrero de 2015.

Bértolo, C. (1989): “Introducción a la narrativa española actual”, Revista del Occidente, 98-99, 29-60.

Cabo Aseguinolaza, F. y Candelas Colodrón, M. Á. (1986): “Julio Llamazares: la simbología ambigua de la memoria», en V. García de la Concha et alii (eds.) (1986) Literatura contemporánea en Castilla y León, Valladolid, Junta de Castilla y León: 277-280.

Cañas, D. (1989): “El sujeto poético posmoderno”, Ínsula, 512-513, 52-53.

Castro, A. (1988): “La literatura es como un iceberg”, El Día, 23 de abril de 1988.

Demicheli, T. H. (1988): “Julio Llamazares: uno escribe siempre de lo que tiene y de lo que ha perdido", $A B C, 24$ de marzo de 1988.

Fusi, J. P. (1996): “Una dictadura personal y militar», en AA.VV. (1992) 1975-1995. Veinte años de nuestra vida. Historia de la democracia, capítulo 2, Madrid, El Mundo: 41.

García, A. (1983): "Poesía del recuerdo", Cuadernos del Norte, 22, 91-93.

García de Cortázar, F. y González Vesga, J. M. (1994): Breve historia de España, Madrid, Alianza Editorial.

García de la Concha, V. (1996): “Panorama de la poesía en Castilla y León: 1940-1985 (Esbozo)", en V. García de la Concha et alii (eds.) (1996) Literatura contemporánea en Castilla y León, Valladolid, Junta de Castilla y León: 13-33.

García Martín, J. L. (1992): “La poesía”, en F. Rico y D. Villanueva (eds.) (1992) Historia y crítica de la literatura española. Los nuevos nombres: 1975-1990, Barcelona, Editorial Crítica: 94-156.

Iriart, C. (1988): “Entrevista a Julio Llamazares", El Ideal Gallego, 18 de mayo de 1988.

Iturbe, A.: "Julio Llamazares, Distintas formas de mirar el agua", http:/ / www.librujula. com/criticas/337-distintas-formas-de-mirar-el-agua 
(Consultado el 6 de febrero de 2017).

Izquierdo, J. M. (1995): “Julio Llamazares: Un discurso neorromántico en la narrativa española de los ochenta", Iberoromania, 55-67.

Justicia Segovia, A. (1987): “Éxodo rural y descapitalización humana del campo: la provincia de Málaga", Baética, Estudios de arte, geografía e historia, 10, 31-66.

Lussón, F. (1988): “Sólo quiero escribir lo que me dicta la memoria", La Vanguardia, 24 de marzo de 1988.

Mainer, J.-C. (2015): “Voces sobre las aguas”, El País, 13 de febrero de 2015.

Martínez Ruiz, E.; Maqueda, C. y Diego, E. de. (1999): Atlas histórico de España II, Madrid, Istmo.

Mendoza, A.: "Julio Llamazares: «Ser apatrida te da mayor libertad»", https:/ / www. efe.com/efe/ espana/cultura/julio-llamazares-ser-apatrida-te-da-mayorlibertad/10005-2535469\# (Consultado el 12 de febrero de 2015).

Miñambres, N. (1988): "La lluvia amarilla de Julio Llamazares: el dramatismo lírico y simbólico del mundo rural”, Ínsula, 502, 20.

Olivares, P.: “Distintas formas de mirar el agua”, http:/ / www.factorcritico.es/ distintasformas-de-mirar-el-agua/ (Consultado el 11 de abril de 2015).

Ortiz, B. (2015): "Hay mucho dolor tras el gesto cotidiano de abrir un grifo", GranadaHoy, 1 de marzo de 2015.

Parreño, J. M. (1984): “Poesía joven de Madrid”, Ínsula, 454, 6.

Pérez, J. ([2000] 2006): Historia de España (traducción Juan Vivanco, Magda Mirabet, M. ${ }^{a}$ Carmen Doñate), tercera edición, Barcelona, Crítica.

Pintor, J. (2015): “En la ciudad de la lluvia”, Qué Leer, 208, 44-45.

Plaza, J. M. (2015): “Llamazares vuelve a casa”, El Mundo, 13 de febrero de 2015.

Ponte Far, J. A. (1988): "Reflexión poética sobre la soledad», La Voz de Galicia, 30 de junio de 1988.

Prado, B. (1988): “Julio Llamazares: Soy un escritor romántico”, Diario 16, 25 de marzo de 1988.

Puente, A. (1988): “Julio Llamazares, con ilusión, sin esperanza”, Nueva España, 10 de abril de 1988 .

Reñones Díaz, J. (2003): “El abandono del mundo rural”, Diario de León, 20 de enero de 2003.

Rico, F. (1991): “De hoy para mañana, El País, 9 de octubre de 1991.

Rodríguez Marcos, J. (2015): “Julio Llamazares: «La memoria histórica de un país es su literatura»", El País, Babelia, 14 de febrero de 2015.

Rodríguez Zúñiga, L. (1985): “Sobre la sociedad española actual”, Revista de Occidente, $50,103-114$.

Roglan, J. (1990): “Un viajero que vadea la quiebra de una cultura”, El Periódico, 2 de febrero de 1990. 
Sanz,I.:"Distintas formas de mirar elagua,Julio Llamazares", http:/ / latormentaenunvaso. blogspot.gr / 2015\% 20/02/distintas-formas-de-mirar-el-agua-julio.html (Consultado el 19 de febrero de 2015).

Sanz, J. (1988): “Julio Llamazares: la soledad, la memoria”, Campo Soriano, 18 de febrero de 1988.

Subirats, E. (1995): España miradas fin de siglo, Madrid, Ediciones Akal.

Témime, É.; Broder, A. y Chastagnaret, G. ([1979] 1982): Historia de la España contemporánea. Desde 1808 hasta nuestros días (traducción Albert Carreras), Barcelona, Ariel, 1982.

Torres del Moral, A. ([1985] 1988): Principios de derecho constitucional español (1er tomo) segunda edición, Madrid, Atomo Ediciones.

Val, T.: "La fuerza de lo auténtico" http://revistamercurio.es/lecturas/narrativa/lafuerza-de-lo-autentico/ (Consultado el 15 de julio de 2015).

Vilar, P. ([1963] 1990): Historia de España (traducción Manuel Tuñón de Lara \& Jesús Suso Soria), vigésima novena edición, Barcelona, Crítica.

Villena, L. A. de (1986) Postnovísimos, Madrid, Visor. 